\title{
Aggression and ambient temperature: The facilitating and inhibiting effects of hot and cold environments
}

\author{
PAUL A. BELL \\ Colorado State University, Fort Collins, Colorado 80523 \\ and \\ ROBERT A. BARON \\ Purdue University, Lafayette, Indiana 47907
}

\begin{abstract}
Seventy-two undergraduate males received either a very positive or very negative personal evaluation from a confederate, and were later given an opportunity to aggress against this individual by means of electric shock. Ambient temperature in the experimental sessions was held at either a relatively cold $\left(64^{\circ} \mathrm{F}\right)$, cool $\left(72^{\circ} \mathrm{F}\right)$, warm $\left(85^{\circ} \mathrm{F}\right)$, or hot $\left(93^{\circ} \mathrm{F}\right)$ level. It was predicted that as the amount of negative affect induced among subjects by the experimental conditions increased to moderate levels, aggression toward the victim would rise, but that at more extreme degrees of negative affect, the intensity of aggression would level off and begin to decline. Results were consistent with these predictions, and a significant $(p<.05)$ curvilinear relationship was found between negative affect and aggression.
\end{abstract}

In a series of recent studies, Baron and Bell (1975, 1976) suggested that the relatonship between high ambient temperatures and human aggression is mediated in a complex manner by negative affective reactions. More specifically, in accordance with the data from four experiments, these researchers proposed that moderate levels of negative affect, such as those produced by provocation alone or by unpleasantly high ambient temperatures alone, tend to facilitate overt attacks against other human beings, whereas more extreme levels of negative affect, such as those produced by the combination of strong provocation and uncomfortably high ambient temperatures, actually tend to inhibit aggression. Underlying this suggestion of a curvilinear relationship between negative affect and aggression is the rationale that, under moderate degrees of negative affect, aggression is a dominant response in subjects' behavior hierarchies, so that aggressive behavior is consequently facilitated. On the other hand, more extreme levels of negative affect reduce aggression by increasing the dominance of other types of responses (e.g., flight tendencies, attempts to minimize discomfort) which are incompatible with the overt expression of aggression (see also Bandura, 1973; Bell \& Baron, 1976; Buss, 1961).

This research was supported by NSF Grant GS-35276 to Robert A. Baron. Appreciation is expressed to Sally Colussy, Jerry Eckert, Rosemary Martinak, Steve McCormick, Howie Miller, and Jane Russell for their assistance in the data collection. Reprint requests should be sent to Paul A. Bell, Department of Psychology, Colorado State University, Fort Collins, Colorado 80523.
A logical extension of this suggestion is that exposure to uncomfortably cold, as well as uncomfortably hot, ambient temperatures should lead to negative affective reactions. Thus, according to the hypothesis of a curvilinear (inverted-U) relationship between negative affect and aggression, one would expect that moderately negative affect associated with exposure to cold ambient temperatures alone would facilitate aggression. If, however, exposure to cold ambient temperatures is combined with other sources of negative affect, such as negative personal evaluations, the level of negative affect will be high and aggression may be reduced.

The purpose of the present experiment, then, was that of extending the findings of previous research by examining the effects on aggression of exposure to an unpleasantly cold environment. Thus, subjects in the present study were exposed to either a positive or negative personal evaluation from a confederate of the experimenter under ambient temperature conditions that were either cold $\left(63^{\circ}-65^{\circ} \mathrm{F}\right)$, cool $\left(71^{\circ}-73^{\circ} \mathrm{F}\right)$, warm $\left(84^{\circ}-86^{\circ} \mathrm{F}\right)$, or hot $\left(92^{\circ}-94^{\circ} \mathrm{F}\right)$. It was predicted that uncomfortably cold or hot temperatures would facilitate aggression for subjects receiving a positive personal evaluation, but that such uncomfortable temperatures would decrease aggression for subjects receiving negative personal evaluations.

\section{METHOD}

Seventy-two males enrolled in elementary psychology participated in the experiment. Participation satisfied part of a course requirement. Nine subjects were randomly assigned to each cell 
of a 4 by 2 factorial design, which was based on four levels of ambient temperature (cold, cool, warm, hot) and two types of personal evaluation (positive, negative). The apparatus consisted of a modified Buss "aggression machine" (Buss, 1961) identical to that used in previous research (e.g., Baron \& Bell, 1975). This apparatus contained 10 pushbutton switches numbered consecutively from 1 to 10 , which ostensibly could be used to deliver electric shocks of varying intensity and duration to another individual.

Procedures followed those of Baron and Bell $(1975,1976)$. Briefly, each subject participated with a male confederate posing as another subject. A female experimenter initially asked both individuals to complete a set of personal feelings scales (see, e.g., Griffitt, 1970). These scales, which served as the index of affective state, consisted of six 7-point semantic differential scales (comfortable-uncomfortable, bad-good, high-low, pleasantunpleasant, and negative-positive). It was then arranged for the subject and confederate to evaluate each other on the basis of personality sketches they wrote about themselves. In the negative evaluation condition, the confederate responded to the subject's personality sketch by describing him unfavorably (e.g., insincere, immature, below average in intelligence); in the positive evaluation condition, the subject was described in favorable terms (e.g., sincere, mature, above average in intelligence). After the subject examined the confederate's evaluation of him, the experimenter asked both subjects to complete another personal feelings scale.

The experimenter next explained that in order to study the effects of temperature and humidity upon physiological reactions to electric shock, one of the subjects would serve as a responder and receive a series of shocks from the other subject, who would serve as a stimulater. The confederate was chosen to serve as the responder and, following his consent, was conducted into an adjoining room where he was ostensibly connected to an impressive-looking polygraph. After pretending to give the responder instructions for his part in the study, the experimenter explained to the subject that each time a red light on the apparatus went on, the subject could press any of the 10 shock buttons. The experimenter further explained that the higher the number on each of the 10 shock buttons, the stronger the shock to the responder, and the longer a button was depressed, the longer the shock would last. The experimenter then joined the confederate in the next room and conducted 20 shock trials.

Manipulation of ambient temperature was accomplished through appropriate combinations of air conditioners and electric heaters. Average temperatures (and relative humidity) during the experimental sessions were, respectively, $64^{\circ} \mathrm{F}(49 \%)$ in the cold condition, $72^{\circ} \mathrm{F}(45 \%)$ in the cool condition, $85^{\circ} \mathrm{F}$ $(56 \%)$ in the warm condition, and $93^{\circ} \mathrm{F}(44 \%)$ in the hot condition.

\section{RESULTS}

Factorial analyses of variance were performed on the shock intensity and shock duration data, as well as on a transformed dependent measure combining intensity and duration $(Y=\sqrt{X}+\sqrt{X+1}$, where $X=$ intensity $X$ duration). The effect of personal evaluations was reliable for shock intensity $[F(1,64)=5.15, p<.03]$, for shock duration $[F(1,64)=7.40, p<.01]$, and for the transform measure $[F(1,64)=9.86, p<.01]$. For all three dependent measures, subjects receiving negative evaluations delivered stronger shocks than subjects receiving positive evaluations. The main effect of tempperature was not reliable for any of the three dependent measures (all $\mathrm{Fs} \leqslant 1.40$ ). However, a marginally reliable Temperature by Evaluation interaction appeared for
Table 1

Shock Duration (seconds) for Subjects in Four Temperature Conditions

\begin{tabular}{llccc}
\hline & \multicolumn{4}{c}{ Ambient Temperature } \\
\cline { 2 - 5 } $\begin{array}{c}\text { Personal } \\
\text { Evaluation }\end{array}$ & $\begin{array}{c}\text { Cold } \\
\left(64^{\circ} \mathrm{F}\right)\end{array}$ & $\begin{array}{c}\text { Cool } \\
\left(72^{\circ} \mathrm{F}\right)\end{array}$ & $\begin{array}{c}\text { Warm } \\
\left(86^{\circ} \mathrm{F}\right)\end{array}$ & $\begin{array}{c}\text { Hot } \\
\left(93^{\circ} \mathrm{F}\right)\end{array}$ \\
\hline Positive & $.42_{\mathrm{ab}}$ & $.35_{\mathrm{a}}$ & $.47_{\mathrm{ab}}$ & $.53_{\mathrm{b}}$ \\
Negative & $.53_{\mathrm{b}}$ & $.67_{\mathrm{c}}$ & $.72_{\mathrm{c}}$ & $.47_{\mathrm{ab}}$ \\
\hline
\end{tabular}

Note-Means which do not share a common subscript differ at the .05 level by the Duncan multiple range test.

shock duration $[F(3,64)=2.29, p<.09]$. Since the pattern of means for this measure was in the predicted direction (see Table 1), the means were compared with each other using the Duncan multiple range procedure. As predicted, subjects receiving positive personal evaluations delivered longer shocks in the uncomfortably hot condition than in the comfortably cool condition. However, subjects receiving negative personal evaluations actually delivered longer shocks in the cool than in the hot environment. Moreover, consistent with predictions, the uncomfortably cold environment reduced aggression relative to the more comfortable cool environment for subjects in the negative evaluation condition. Within the cool and warm temperature conditions, negative personal evaluations reliably increased aggression; but, as anticipated, within the cold and hot conditions the additional negative affect from negative personal evaluations did not further increase aggression.

In order to test the hypothesis of a curvilinear relationship between negative affect and aggression directly, affect was treated statistically as an independent variable in a between-groups trend analysis on the aggression data. The measure of affect employed for these purposes was the change score calculated by subtracting a subject's total score on the initial personal feelings scales from his total score on the second administration of these scales. (The personal feelings scales were scored by summing the subject's responses on each of the six bipolar scales, with the negative end scored 1 , the positive end 7.) An analysis of variance performed on these' affect scores revealed a marginally reliable difference across all groups $[F(7,64)=1.76, p<.11]$. In the trend analysis for the shock data, the quadratic component was reliable $(p<.05)$ for all three measures of aggression, and the tests for higher order components were never reliable $(\mathrm{Fs}<2.0)$. The linear component was reliable only for the transform measure $[F(1,64)=$ $4.57, \mathrm{p}<.05]$. As expected, for all three measures, aggression was greatest under moderately negative affective conditions, and less pronounced under conditions of either positive affect or extremely negative affect.

\section{DISCUSSION}

The results of the present investigation are generally consistent with previous findings on the relationship between ambient 
temperature and aggression (Baron \& Bell, 1975, 1976; Bell \& Baron, 1976). More specifically, the current findings suggest that moderate levels of negative affect, such as those associated with negative personal evaluations under cool and pleasant ambient temperatures or with positive or negative personal evaluations under warmer and more unpleasant ambient temperatures, may facilitate overt aggressive behavior against another individual. More extreme levels of negative affect, however, such as those associated with negative personal evaluations under very hot ambient temperature conditions, will not further facilitate aggressive activity, and may actually tend to inhibit such behavior. Furthermore, the results of the present study suggest that exposure to uncomfortably cold ambient temperatures may have the same effects on aggressive tendencies as does exposure to uncomfortably hot ambient temperatures.

In conclusion, it may be stated that aggression may be influenced by exposure to high or low ambient temperatures. However, whether aggression is facilitated or inhibited by such environmental circumstances may depend on whether the overall affective state of the individual is moderate or more extreme. It may well be that exposure to unusually high or low ambient temperatures, whether by act of nature or by conditions necessitating regulation of thermostatic settings, can influence hostile behavior.

\section{REFERENCES}

Bandura, A. Aggression: A social learning analysis. Englewood Cliffs, N.J: Prentice-Hall, 1973.

Baron, R. A., \& Bell, P. A. Aggression and heat: Mediating effects of prior provocation and exposure to an aggressive model. Journal of Personality and Social Psychology, 1975, 31, 825-832.

Baron, R. A., \& Bell, P. A. Aggression and heat: The influence of ambient temperature, negative affect, and a cooling drink on physical aggression. Journal of Personality and Social Psychology, 1976, 33, 245-255.

Bell, P. A., \& Baron, R. A. Aggression and heat: The mediating role of negative affect. Journal of Applied Social Psychology, 1976, 6, 18-30.

Buss, A. H. The psychology of aggression. New York: Wiley, 1961. GRIFFITT, W. Environmental effects on interpersonal affective behavior: Ambient effective temperature and attraction. Journal of Personality and Social Psychology, 1970, 15, 240-244.

(Received for publication January 29, 1977.) 